Sale of kids was the most important source of income from goat rearing. Sixty-six percent of the goats sold during the study period (101 out of 154) were 3 to 6 months old; $28 \%$ were 6 to 12 months old and only $6 \%$ were younger than 3 months. The average sale price was Rs.122 per kg live weight. The sale price obtained from sale of 3 to 6 month old goats was $8 \%$ higher than the average (i.e. Rs.131 per $\mathrm{kg}$ live weight).

The important constraints to village goat rearing were found to be the lack of selected breeding bucks, shortage of grazing, browsing and fodder in the summer, inadequacy of veterinary health care and uncontrolled breeding leading to early breeding of young does and consequent loss of the first kid crop of these young does.

The AICRP scheme has made available an opportunity to start performance recording and simple genetic improvement programmes among village goats of different Indian breeds. These need to be combined with goat management improvement including training of goat owners in basic veterinary health care, appropriate feeding management using local resources and breeding management to maximize productivity. Goat owners also need to be organized so that they can take advantage of subsidized bank loans to purchase goats. Such organizations can then be empowered to carry on performance recording, insurance, training, common property management, fodder resource enhancement programmes and other beneficial activities. NARI will collaborate with other NGO such as Paryay in the Osmanabad district in Maharashtra to establish a model goat improvement scheme.

\title{
Impact of the type of experimental infection with Haemonchus contortus and post-weaning parasitism level on genetic evaluation of the resistance of Creole kids
}

\author{
Jean-Christophe Bambou ${ }^{\dagger}$, Rémy Arquet, Maurice Mahieu and Nathalie Mandonnet \\ INRA, UR143, Unité de Recherches Zootechniques, 97170 Petit Bourg, Guadeloupe (FWI)
}

\begin{abstract}
Introduction
Naturally infected tropical pastures allow genetic evaluation of Creole goat resistance to gastrointestinal strongyles (Mandonnet et al., 2006). The Creole goats of INRA-Gardel herd are now indexed on their resistance under mixed natural infection conditions. However infection levels and proportions between Haemonchus contortus, Trichostrongylus colubriformis and Oesophagostomum columbianum populations vary across seasons and pasture management. The aim of this study was to test the impact of the level of post-weaning natural infection at pasture and the type of experimental infection on a standardized evaluation design of genetic resistance in Creole kids. We compared the differences between four levels of natural infection at pasture and two experimental infection types (single, SI; and trickle, TI) with H. contortus. Our hypothesis that animals may respond differently was based on the fact that the mixed grazing system reduces the parasite burden at pasture (Mahieu et al., unpublished data) and TI better mimics natural infection.
\end{abstract}

\section{Materials and Methods}

Three trials were involved in this study with a total of 169 male kids chosen from 3 successive cohorts of the Creole flock of INRA-Gardel in 2009 and 2010. Kids were reared at pasture from 3 months (weaning) until 7 months of age into a mixed grazing system with Creole cattle. Kids were allocated in 4 grazing groups according to the stocking rate based on the metabolic live weight $\left(\mathrm{LW}^{0.75}\right): 25 \%\left(\mathrm{kids}^{150 \mathrm{~kg} \mathrm{LW}} \mathrm{LW}^{0.75}\right.$ and cattle $450 \mathrm{~kg} \mathrm{LW}{ }^{0.75}$ ), $50 \%$ (kids $300 \mathrm{~kg} \mathrm{LW}$ L.75 $^{0}$ and cattle $300 \mathrm{~kg} \mathrm{LW}^{0.75}$ ), $75 \%$ (kids $450 \mathrm{~kg} \mathrm{LW} \mathrm{LW}^{0.75}$ and cattle $150 \mathrm{~kg} \mathrm{LW}{ }^{0.75}$ ) and $100 \%$ (kids $600 \mathrm{~kg} \mathrm{LW}^{0.75}$ ). The pedigree of each animal was available from the foundation generation of 1979 and each animal was genetically indexed for faecal egg counts (FEC) at 11 months of age. Four months before experimental infections, kids were drenched, housed, and fed a forage diet based on Dichanthium spp., mineral licks and tap water ad libitum. During this period, limited nematode infection occurred but without any clinical signs. At 10 months (one month before beginning the experiment), the kids were drenched and they received ad libitum parasite-free Dichanthium spp. hay. At 11 months they were allocated into 2 groups according to the infection type. At day 0 (D0), experimental infection was induced with a single dose of $10,000 \mathrm{H}$. contortus $\mathrm{L}_{3}(\mathrm{SI}, n=84)$ or $1,000 \mathrm{~L}_{3} /$ day during ten days $(\mathrm{TI}, n=85)$. Each infected group was constituted of one half resistant (R) and one half susceptible (S) genetic indexed kids. FEC, packed cell volume (PCV), blood eosinophilia (EOSI) were weekly recorded until D42 after infection. Kinetics of each variable was modelled using mixed procedure of SAS software release 3.1 (SAS institute Inc., 1999).

${ }^{\dagger}$ E-mail: Jean-Christophe.Bambou@antilles.inra.fr 


\title{
Results and Discussion
}

The FEC, EOSI and PCV significantly varied across the experimental infection $(P<0.001)$. Infection type did not affect FEC and PCV. FEC increased until the end of the infection (D35) and was two fold higher in R than in $S$ kids $(P<0.0001)$. The PCV decreased significantly $(P<0.0001)$ but no difference was observed between $\mathrm{R}$ and $\mathrm{S}$ kids. These results suggest that experimental infection with a single dose of $10,000 \mathrm{H}$. contortus $L_{3}$ could lead to a standardized genetic evaluation design for resistance to strongyles in Creole goats. Infection type affected EOSI $(P<0.05)$, basically at D42 $\left(792.10^{3}\right.$ cells $/ \mathrm{mL}$ vs $513.10^{3}$ cells $/ \mathrm{mL}$, in $\mathrm{TI}$ and SI respectively). These data are so far consistent with a role of eosinophils in the killing of infective larval stages, but not adults, of most helminths (Meeusen et al., 2005). The post-weaning grazing management affected FEC $(P=0.0003)$ but not EOSI and PCV. During experimental infection, FEC was higher in animals from grazing group $25 \%$ than $75 \%$ and $100 \%(P<0.0001)$. No interaction of grazing management $\times$ genetic status was observed. Here we showed that without any effect on genetic status, the level of infection of kids during the post-weaning period could help in preventing severe infection rate at the adult stage. The results suggest that stimulation of the immune system in young animals increase the efficiency of the protective immune response at a further stage. This result needs further studies to understand the mechanisms underlying this observation.

\section{Conclusion}

Standardized genetic evaluation design for resistance to gastrointestinal strongyles in Creole goats could be realized with a single dose of $10,000 \mathrm{H}$. contortus $\mathrm{L} 3$. The level of post-weaning natural parasitism at pasture would not influence the genetic status evaluation. More generally our results suggest that it would be better to expose young kids to a high level of gastrointestinal parasitism in order to increase to basal level of resistance thereafter.

\section{References}

Mandonnet N, Menendez-Buxadera A, Arquet R, Mahieu M, Bachand M and Aumont G 2006. Genetic variability in resistance to gastro-intestinal strongyles during early lactation in Creole goats. Animal Science 82, 283-287.

Meeusen ENT, Balic A and Bowles V 2005. Cells, cytokines and other molecules associated with rejection of gastrointestinal nematode parasites. Veterinary Immunology and Immunopathology 108, 121-125.

\section{Assessment of genetic variability of resistance to heartwater in Creole goats}

\author{
J. C. Bambou ${ }^{1 \dagger}$, N. Vachiery' ${ }^{2}$ P. Despois ${ }^{3}$, K. Giraud-Girard ${ }^{2}$, R. Arquet $^{3}$, V. Pinarello ${ }^{2}$, \\ R. Aprelon ${ }^{2}$, C. Barbier ${ }^{3}$, J. Gobardham ${ }^{3}$, N. Mandonnet ${ }^{1}$ and T. Lefrançois ${ }^{2}$
}

${ }^{1}$ INRA UR 143, Centre Antilles Guyane, domaine Duclos, 97170 Petit Bourg, Guadeloupe (FWI); ${ }^{2}$ CIRAD UMR CMAEE, domaine Duclos, 97170 Petit Bourg, Guadeloupe, France; ${ }^{3}$ INRA UE 1294, domaine Duclos, 97170 Petit Bourg, Guadeloupe, France

\section{Introduction}

In the Caribbean as in many other parts of the tropical area, gastrointestinal strongylosis (GIS) and heartwater are the two main threats on small ruminant production and especially on goat production. Even if several studies have been done on heartwater immune response with a protective cellular immune response, the protective mechanisms are still unclear. A collaborative research program has been carried out in Guadeloupe between CIRAD and INRA to analyse resistance to GIS and heartwater, including their relationship. The first step of this program is to validate the hypothesis of a genetic variability in resistance to heartwater.

\section{Material and methods}

Eleven Creole bucks were evaluated on the resistance/susceptibility of their offsprings to an Ehrlichia ruminantium standardized subletal infection inducing $70 \%$ of mortality (Vachiery et al., 2006). Two susceptible and 2 resistant bucks were chosen among them and were randomly mated to 22 does. Forty-three kids, allocated in 2 cohorts of 21 and 22 kids, were separated from mother and reared indoors in order to avoid transfer of mother immunity and tick infestation until the challenge at yearling. The intensity of the disease was quantified using clinical reaction indices (incubation period, intensity of fever, nervous signs, death) as already described by Vachiery et al. (2006). Clinical indices were indicators of intensity of the disease. Clinical scores were defined as the sum of each clinical reaction indices per animal and per day, added up over the period. A square root transformation was applied in order to normalize residual variances. Repeated measures

\footnotetext{
† E-mail: Jean-Christophe.Bambou@antilles.inra.fr
} 